\title{
A CLINICOPATHOLOGICAL STUDY OF FOURNIER'S GANGRENE AND ITS MANAGEMENT: EARLY DEBRIDEMENT BETTER PROGNOSIS
}

\author{
Brijesh Singh ${ }^{1}$, Aruna Singh ${ }^{2}$, Arun Kumar Patel ${ }^{3}$
}

${ }^{1}$ Assistant Professor, Department of General Surgery, S. S. Medical College, Rewa, Madhya Pradesh.

${ }^{2}$ Associate Professor, Department of Physiology, S. S. Medical College, Rewa, Madhya Pradesh.

${ }^{3}$ Professor, Department of ENT, Jhalawar Medical College, Jhalawar, Rajasthan.

\begin{tabular}{l} 
ABSTRACT \\
\hline BACKGROUND \\
Fournier's Gangrene (FG) is a rare, but life-threatening disease. FG has been shown to have a predilection for patients with \\
diabetes as well as long-term alcohol misuse. FG is a mixed infection caused by both aerobic and anaerobic bacterial flora. The \\
development and progression of the gangrene is often fulminating and can rapidly cause multiple organ failure and death.
\end{tabular}

AIM

To assess the predisposing factors various clinical presentations, common causative organisms and culture sensitivity, histopathological findings and treatment of Fournier's gangrene.

\section{STUDY DESIGN}

A prospective study conducted over a period from disclosure, Dec 2014 to Nov 2015 in a tertiary care institute.

\section{RESULTS}

In our study of 50 cases, all the patients were males. Incidence of Fournier's gangrene in general surgical admission is $0.69 \%$. The mean age of presentation was 50.14 years with age range of 20 to 85 years and most of the patients were in the age group 3645 years (38\%). In 44 patients (88\%), there was a history of associated co-morbid condition; 36 cases $(72 \%)$ of diabetes mellitus, 34 cases (64\%) poor personal hygiene, 31 cases (62\%) low socioeconomic status, 28 cases (56\%) chronic alcoholisms, 17 cases (34\%) hypertension, 3 cases (6\%) HIV infection and 1 case (2\%) was of malignancy, while in 6 patients (12\%) we could not identify any underlying co-morbid condition. Type 1 was the most common type of Fournier gangrene, in which the E. Coli was the most common organism isolated (64\%). Surgical debridement was done in all the cases after the initial fluid resuscitation and empirical broad spectrum antibiotic treatment. Mortality was low (4\%) in our study because of early and aggressive management of disease.

\section{CONCLUSION}

Fournier's gangrene is more common in middle aged males. Diabetes mellitus is the most common co-morbid condition associated with necrotizing fasciitis. The perineum is commonly affected. The presence of multiple co-morbid conditions reduces the survival. Early diagnosis and aggressive surgical debridement reduces mortality.

\section{KEYWORDS}

Fournier's Gangrene, Early Debridement, Outcome.

HOW TO CITE THIS ARTICLE: Singh B, Singh A, Patel AK. A clinicopathological study of Fournier's gangrene and its management: early debridement better prognosis. J. Evolution Med. Dent. Sci. 2016;5(15):688-691, DOI: 10.14260/jemds/2016/159

\section{INTRODUCTION}

Fournier's gangrene is a fulminant synergistic necrotizing fasciitis of the scrotum, penis, perineum first described by French venereologist Jean A. Fournier in 1883.(1) This is more commonly seen in middle aged having immunosuppressive disorder like diabetes mellitus, malignancy and chronic alcoholism.(2) Despite aggressive treatment, it has high mortality rate.(3) on the basis of transcript from an 1883 clinical lecture, in which Fournier presented a case of perineal gangrene in an otherwise healthy young man.

Financial or Other, Competing Interest: None.

Submission 06-01-2016, Peer Review 03-02-2016,

Acceptance 08-02-2016, Published 20-02-2016.

Corresponding Author:

Dr. Brijesh Singh,

MIG-18, Housing Board Colony,

Bodabag, Rewa-486001,

Madhya Pradesh.

E-mail: drbrijeshsinghrewa@gmail.com

DOI: 10.14260/jemds/2016/159
On the basis of bacteriology, Fournier's gangrene is divided into two types-Type 1 and Type 2 . In type 1 , infection is mostly mixed infection from aerobic and anaerobic bacteria including group A haemolytic streptococci, Staphylococcus aureus, E. coli, clostridium and bacteroides, etc. In type 2, infection is caused by group A haemolytic streptococci possibly with a co-infection by S Aureus.[4] This is more commonly seen in middle aged and elderly people.[5,6] It is commonly associated with immunocompromised condition such as diabetes mellitus, chronic alcoholisms, poor personal hygiene, low socioeconomic status, malnutrition, malignancy, HIV infection, chronic renal and liver disease. $[7,8,9]$

Pathologically, the disease is believed to be an obliterative endarteritis caused by the spread of microorganism. Inflammation and oedema from infection results in impaired local blood supply, leading to vascular thrombosis in the cutaneous and subcutaneous tissues. Perifascial dissection with subsequent spread of bacteria and progression to gangrene of the overlying tissues with necrosis of the superficial and deep tissues with polymorphonuclear cell infiltrate.[10] 
Diagnosis is primarily on clinical background, lab test, pus culture, radiological examination and histopathology can aid in the diagnosis. Early and aggressive treatment is associated with reduced mortality rate and better outcome and if delayed have a negative impact on prognosis.(11)

\section{MATERIAL AND METHODS}

The study was conducted in the Department of General Surgery and Pathology over a period from Dec. 2014 to Nov. 2015. Fifty cases of Fournier's gangrene were studied. All male patients of age more than 16 years will be included in this study. Data collected for each patient's included age, sex associated co-morbid condition. Predisposing factors, addiction, clinical parameters (Pyrexia duration of symptoms, presence of hypotension), laboratory parameters (Haemoglobin, total leucocyte count, blood sugar, serum albumin, serum creatinine), bacteriology and final outcome.

\section{OBSERVATIONS}

The mean age of presentation was 50.14 years (Ranged from 20-85 years) with majority of the patients were in the age group of 36-45 years (38\%). The scrotum was the most common site involved. In our study involvement of scrotum and perianal was $82 \%$ and $18 \%$, respectively. More than $85 \%$ of the patients have an initiating etiology (Boil 32\%, urethral stricture $14 \%$, trivial trauma $20 \%$, perianal abscess $18 \%$ and indwelling catheter $4 \%$ ) that lead to the development of Fournier's gangrene.

\section{BACTERIOLOGY}

The bacteriology of Fournier's gangrene in this study was characterized by a wide variety of organisms, cultured from affected wounds. The most cultures were polymicrobial (Type-1) found in 43 patients (86\%) and monomicrobial (Type-2) was found in 7 patients (14\%). In polymicrobial, the most common organisms isolated was E. coli found in 32 cases (64\%), the other organisms isolated were Klebsiella (56\%) Proteus (42\%), Pseudomonas (46\%) acinetobacter (8\%), Staphylococcus aureus (20\%), streptococcal group A (14\%). The most common anaerobic organism isolated were bacteroides found in (36\%) cases, while other anaerobes were Actinomyces (6\%) and Peptostreptococcus (10\%). In our study a mean of 3.09 cultures were isolated from each Polymicrobial.

\begin{tabular}{|c|c|c|c|c|}
\hline Bacteria & No. of Patients & & \multicolumn{2}{|c|}{ Percentage (\%) } \\
\hline \multirow{8}{*}{ Aerobes } & \multirow{3}{*}{ Gram +ve } & Staphylococci & 10 & 20 \\
\hline & & Streptococci & 7 & 14 \\
\hline & & Enterococci & 5 & 10 \\
\hline & \multirow{5}{*}{ Gram -ve } & E. coli & 32 & 64 \\
\hline & & Klebsiella & 28 & 56 \\
\hline & & Proteus & 21 & 42 \\
\hline & & Pseudomonas & 23 & 46 \\
\hline & & Acinetobacter & 8 & 16 \\
\hline \multirow{3}{*}{ Anaerobes } & \multirow{2}{*}{ Gram +ve } & Pseudostreptococcus & 5 & 10 \\
\hline & & Actinomycin & 3 & 6 \\
\hline & Gram -ve & Bacteroides & 18 & 36 \\
\hline Fungal & Candida Albicans & 1 & 2 & \\
\hline \multicolumn{5}{|c|}{ Table 1: Organism isolated in this study } \\
\hline
\end{tabular}

\begin{tabular}{|c|c|}
\hline \multicolumn{2}{|c|}{ Age } \\
\hline$\leq 50$ years & $\mathrm{n}=42$ \\
\hline$>50$ years & $\mathrm{n}=8$ \\
\hline \multicolumn{2}{|c|}{ Duration of symptoms } \\
\hline$\leq 5$ days & $\mathrm{n}=33$ \\
\hline$>5$ days & $\mathrm{n}=17$ \\
\hline \multicolumn{2}{|c|}{ Pyrexia } \\
\hline \multicolumn{2}{|c|}{ Systolic blood pressure } \\
\hline$\geq 100.5 \mathrm{~F}$ & $\mathrm{n}=13$ \\
\hline$<100 \mathrm{mmHg}$ & $\mathrm{n}=37$ \\
\hline$\geq 100 \mathrm{mmHg}$ & Table 2: Clinical Parameters at presentations \\
\hline
\end{tabular}

\begin{tabular}{|c|c|}
\hline \multicolumn{2}{|c|}{ Haemoglobin } \\
\hline$<10 \mathrm{gm} \%$ & $\mathrm{n}=36$ \\
\hline$\geq 10 \mathrm{gm} \%$ & $\mathrm{n}=14$ \\
\hline \multicolumn{2}{|c|}{ Total leucocyte count } \\
\hline$<14000 / \mathrm{mm} 3$ & $\mathrm{n}=42$ \\
\hline$\geq 14000 / \mathrm{mm} 3$ & $\mathrm{n}=8$ \\
\hline \multicolumn{2}{|c|}{ Blood sugar } \\
\hline$<180 \mathrm{mg} \%$ & $\mathrm{n}=31$ \\
\hline$\geq 180 \mathrm{mg} \%$ & $\mathrm{n}=19$ \\
\hline \multicolumn{2}{|c|}{ Serum albumin } \\
\hline$<3 \mathrm{gm} / \mathrm{dl}$ & $\mathrm{n}=16$ \\
\hline$\geq 3 \mathrm{gm} / \mathrm{dl}$ & $\mathrm{n}=34$ \\
\hline \multicolumn{2}{|c|}{ Serum creatinine } \\
\hline$<1.5 \mathrm{mg} \%$ & $\mathrm{n}=19$ \\
\hline$\geq 1.5 \mathrm{mg} \%$ & $\mathrm{n}=31$ \\
\hline able 3: Biochemic & Imission \\
\hline
\end{tabular}




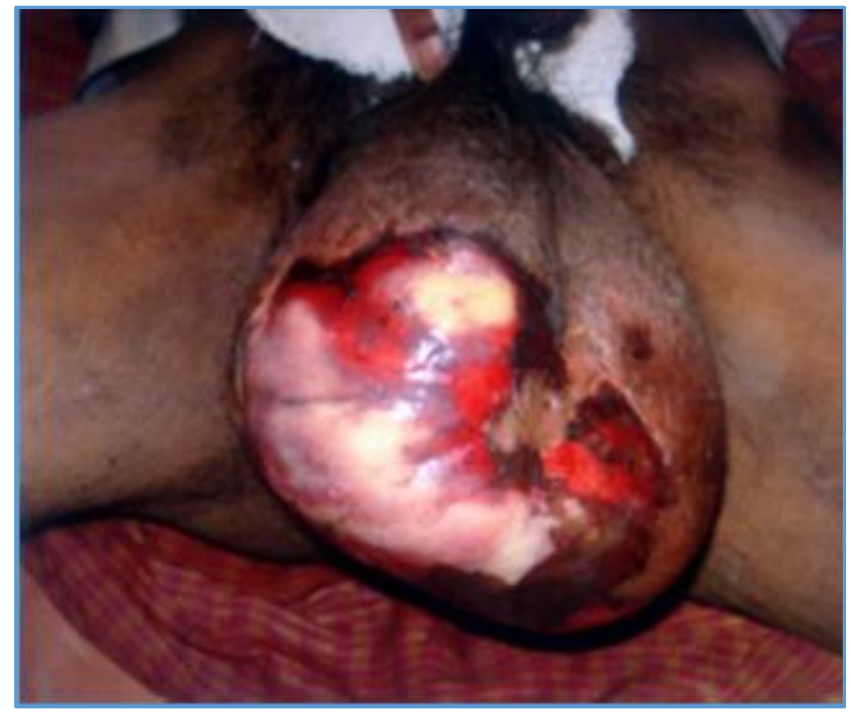

Fig. 1: Fournier's Gangrene involving the Scrotum

The clinical and laboratory parameters are given in Table 2 and 3. It was seen that patients with age $>50$ years, symptoms $>5$ days' duration, systolic blood pressure $<100 \mathrm{mmHg}$ and affected body surface area $>5 \%$ at admission had longer hospital stay. Also patients with leucocytosis $>14000 /$ cumm, blood sugar $>180 \mathrm{mg} / \mathrm{dl}$, serum albumin $<3 \mathrm{gm} / \mathrm{dl}$, serum creatinine $>1.5 \mathrm{mg} \%$ had worse prognosis. Mean duration of symptoms was $5.16 \pm 0.902$ days. Number of debridements were $3.84 \pm 0.809$. Early debridement (Within 24 hrs. of admission) had a better prognosis.

\section{TREATMENT}

The treatment includes radical surgical debridement of the entire necrotic tissue done in all patients. Multiple surgical debridements is the rule rather than the exception with an average of 3.12 debridement required per patients. Regular wound dressing with hypertonic saline, broad-spectrum antibiotic and general and aggressive supportive measures is done in all patients.

\section{PROGNOSIS}

The prognosis of Fournier's gangrene depends on age comorbidity and severity of septic syndrome. Prognosis is eventually fatal if surgically not treated.

\section{DISCUSSION}

Fournier's Gangrene is a relatively uncommon infection, usually beginning with insidious onset of pruritus and discomfort of the external genitalia, perineal and perianal regions and characterized by widespread fascial necrosis with relative sparing of skin and underlying muscle leading to obliterative endarteritis resulting in gangrene.[12,13] Patients with necrotizing fasciitis present with local signs of infection and severe pain disproportionate to local findings. They may be associated with systemic toxic manifestations.[14] Systemic manifestations such as hypotension, fever, tachycardia, tachypnea and laboratory findings of leukocytosis and metabolic acidosis are indices of development of sepsis.[15] Necrotizing fasciitis is commonly seen in middle age males.[1-3, 15-16]
In our study $50 \%$ of the patients were between $40-49$ years. Diabetes mellitus was the most common co-morbid condition in our study (42\%), which is correlated with that in other literatures.[1-2, 17] Higher blood sugar in these patients produces a good medium for bacterial growth and predisposes to an environment of low oxygen tension and rich substrate for bacterial growth.[17] Diabetes also causes defective phagocytosis, decreased cellular immunity and microvascular disease with resultant ischemia. Among the diabetic patients in our study, the mean age was higher.

Polymicrobial infection was more common and the scrotum was more commonly affected. The disease is classified as type- 1 when caused by a mixture of aerobic and anaerobic micro-organisms and type- 2 when caused by group A streptococcus alone or synergistic with second organisms (S. aureus, coliforms, bacteroides spp.). Type 1 is common in our study, which is comparable to other study.[18,19,20] According to Paty R, et al.[21] in case of Fournier's gangrene, a 24-hour delay in radical debridement increases the mortality rate by $11.5 \%$; a 6-day delay is associated with a mortality rate of $76 \%$.

Broad spectrum antibiotics against gram positive, gram negative and anaerobic bacteria should be started early in the course of treatment before culture reports are available. Higher mortality has been reported among patients over 50 years of age and among those having atherosclerosis and diabetes.[22] Fischer et al.[23] found no increase in mortality in patients with diabetes.

The prognosis of Fournier's gangrene depends on age comorbidity and severity of septic syndrome. Prognosis is eventually fatal if surgically not treated the patients.[11] Early surgical treatment is the cornerstone of good prognosis in our study.

\section{CONCLUSION}

Necrotizing fasciitis is more common in middle aged males. In present study, poor personal hygiene and low socioeconomic status are the most common associated co-morbid condition other than diabetes mellitus. E. coli is the most common isolated organisms, which were also found in normal colonic and urogenital micro flora. If personal hygiene of external genitalia and perianal region is properly maintained, then we can reduce development of Fournier's gangrene.[24] Early diagnosis and prompt surgical and medical management is mainstay of good prognosis of these patients with reduced mortality.

\section{REFERENCES}

1. Shaikh N. Necrotizing fasciitis: a decade of surgical intensive care experience. Indian J Crit Care Med 2006;10:225-9.

2. Kandil A. Necrotizing fasciitis: study of 20 cases in Shifa Hospital. Palestine Medical Journal 2006;2(3):16-21.

3. Hamad H, Al Mosleh A/W, Al Maslamani Y, et al. The outcome of surgical management of necrotizing fasciitis in Qatar: 8 years results. The Middle East Journal of Emergency Medicine 2001;1(1):3-4.

4. Giuliano A, Lewis F, Hadley K, et al. Bacteriology of necrotizing infection. AM J Surg 1977;134:52-57.

5. Eke N. Fournier's Gangrene: a review of 1726 cases. British Journal of Surgery, vol. 87, no. 6, pp. 1213-1224, 2002. 
6. Pizzorno R, Bonini F, Donelli A, et al. Hyperbaric oxygen therapy in treatment of Fournier's disease in 11 patients. J Urol Sep 1997;158:837-40.

7. Baskin LS, Carroll PR, Cattolica EV, et al. Necrotizing soft tissue infection of the perineum and genitalia. Bacteriology, treatment and risk assessment. Br J Urol 1990;65:524-529.

8. Paty R, Smith AD. Gangrene and Fournier's gangrene. Urol Clin North Am 1992;19:149-55.

9. Benizri E, Fabiani P, Migliori G, et al. Gangrene of the perineum. Urology 1996;47:935-939.

10. Levenson RB, Singh AK, Novelline RA. Radiographics 2008 Mar-Apr; 28(2):519-28.

11. Elliott D, Kufera JA, Myers RA. The microbiology of necrotizing soft tissue infections. AM J Surg 2000; 179: 361-366.

12. Stamenkovic I, Lew PD. Early recognition of potentially fatal necrotizing fasciitis. The use of frozen section biopsy. N Engl J Med 1984 Jun 28;310(26):1689-93. PMID: 6727947.

13. Basoglu M, Gul O, Yildirgan I, et al. Fournier's gangrene: review of fifteen cases. Am Surg 1997;63:1019-21.

14. McHenry CR, Piotrowski JJ, Petrinic D, et al. Determinants of mortality in necrotizing soft tissue infections. Ann Surg 1995;221:558-565.

15. Shah AK, Kumar NB, Gambhir RPS, et al. Integrated clinical pathway for managing necrotizing soft tissue infections. Indian Journal of Surgery 2009;71:254-257.
16. Peer SM, Rodrigues G, Kumar S, et al. A clinic-pathological study of necrotizing fasciitis-an institutional experience, JCPSP 2007;17(5):257-260.

17. Shaikh N. Necrotizing fasciitis and diabetes mellitus. Int J Diab Dev Ctries 2007;27:14-17.

18. Frezza EE, Atlas I. Minimal debridement in the treatment of Fournier's gangrene. Am Surg 1999;65:1031-4.

19. Czymek R, Frank P, Limmer S, et al. Fournier's gangrene: is the female gender a risk factor? Langenbecks Arch Surg 2010;395:173-180.

20. Kaiser RE, Cerra FB. Progressive necrotizing surgical infections: a unified approach. J Trauma 1981;21:34955.

21. Paty R, Smith AD. Gangrene and Fournier's gangrene. Urol Clin North Am 1992;19(1):149-162.

22. Deodhar SD, Shirahatti RG, Sareen AA, et al. Necrotizing fasciitis (a report of 5 cases). J Postgrad Med 1985; 31:170-2.

23. Fischer JR, Conway MJ, Takeshita RT, et al. Necrotizing fasciitis-importance of roentgenographic studies for soft tissue gas. J Amer Med Assoc 1979;241:803-806.

24. Vernon M Pais, Jr, MD; Chief Editor: Bradley Fields Schwartz, DO; FACS. Fournier gangrene clinical presentation. Updated: March 7, 2013. 